\title{
Editorial introduction*
}

\author{
D E L L H Y M E S
}

Journals proliferate. To add another must give pause. Language in Society is the outcome of discussion over several years, as to the desirability of such a step, and as to the sort of journal wanted. The conviction has grown that a journal, devoted to the emerging field of sociolinguistic research, and seeking to perform an integrative role, is indeed needed. Participation in the editorial board of the journal by colleagues in many parts of the world is an indication that sense of such a need is widespread. Interest in sociolinguistic research grows rapidly, yet there is no one place in which its development can be followed; to which a student or interested colleague can be referred; to which one can contribute in the expectation that colleagues will find one's work; to which one can turn for reviews of significant publications in the field. Nor is there a place in which the various disciplinary orientations and intellectual traditions that contribute to sociolinguistic research can come together and achieve a measure of integration, or, at least, mutual clarification.

The timeliness of the journal is evident in the surge of attention to the term, "sociolinguistics;" the roots of the journal go deeper, however, than focus on a word. Any term may prove ephemeral — one can recall the shortlived prominence twenty years ago in the United States of "metalinguistics" for especially the problem of linguistic relativity, and note the only occasional use now of "ethnolinguistics," put forward in that same period as a general term for relations between linguistics and anthropology. In each case, in point of fact, the underlying questions persist, whatever the names - that of linguistic relativity, because semantic differences among languages persist, however careful and complex must be assessment of their significance; and that of the relation between linguistics and anthropology, because anthropologists continue to encounter language in their work, both in the field and when they consider the nature of culture and of man. It is clear that the problems that give rise to interest in "sociolinguistics" will persist, because rooted in realities of social life and its study.

The problems that prompt attention to sociolinguistics are of two main types. One is the patent need for research pertinent to the many ways in which language, especially diversity of language, poses questions of policy and choice. The other is the need, gradually recognized, for control of social factors in linguistic research, and of linguistic factors in social research. Both types of problem arise first as practical matters, for governments, schools, communities, individuals, in the one case,

\footnotetext{
*Editor's note: This is Dell Hymes' introduction to the first issue of Language in Society. It is reprinted with permission, from Language in Society 1(1):1-14, 1972 [Barbara Johnstone].
} 
for disciplines, scholars and scientists, in the other. Both point beyond practical matters to a field concerned with all the interrelations of language and social life, to a general understanding of language as part of social life. Such a field would be comparative and generalizing, as well as descriptive and remedial; in the words of one of our journal's board, its approach would be integrative, not additive; and it would lead, some believe, to a reconstruction of social theory in the light of linguistic methods and findings, and of linguistic theory on a social basis.

Practical problems are salient, theoretical and methodological needs slower to be recognized; yet much of the time those who deal with salient problems are in the position of needing to apply a basic science that does not yet exist. The journal will be attentive to the roots of sociolinguistics in practical concern, but its contribution will be mainly to the development of the scientific field, one that can be basic to, and adequate to, practical concerns. In this way it will serve practical concerns more surely.

I I

The study of language in society may touch upon almost everything in man's world. How can the scope of an integrative approach be defined, and given direction? I would propose, as first approximation to such a definition and goal, THE MEANS OF SPEECH IN HUMAN COMMUNITIES, AND THEIR MEANINGS TO THOSE WHO USE THEM. MEANS OF SPEECH, first as objects of description, for identification and analysisa conception broader than, partly cutting across the common categories of "language" and "dialect," and directing attention to speech varieties, styles, levels, genres, fields, repertoires, routines, acts, and events. MEANs OF SPEECH, second, as objects of explanation, regarding their origins, development, and disuse, as part of the maintenance and transformation of sociocultural orders. THEIR MEANINGS because relevance in sociolinguistic description, as in ordinary linguistic description, involves form-meaning covariation, a sociolinguistic commutation test, as it were, sociolinguistic signs (in José Pedro de Rona's phrase), of which ordinary linguistic features enter into one side, social meanings the other. THEIR MEANINGS, also, because questions of function are fundamental to sociolinguistic research as a matter both of empirical validity and of social responsibility.

Other formulations may be found preferable. What is essential in any formulation is a functional perspective comprehensive enough to support a general theory of language as part of social life, yet specific enough to orient empirical research.

What is desirable, too, is that a formulation of the scope and goals of sociolinguistic research enable us to acknowledge the past on which we draw, and understand its relation to the future toward which we work. For if the term "sociolinguistics" is new, the notion of a study of language concerned with its role in social life is not. To trace its history only in the period of the formation of structural linguistics (in which, for reasons to be given, transformational generative 
grammar should be included), there is William Dwight Whitney's conception of language as a social institution, as an influence on de Saussure; the constellation in France of de Saussure, Durkheim, van Gennep, Meillet and others; in England the tradition of Malinowski and Firth; in the United States the "ethnologic-linguistic school" (to use Bloomfield's phrase) of Boas, Kroeber, Bloomfield, Sapir, Whorf, and others; the pre-war Prague School of Mathesius, Trubetskoy, Jakobson, and others. Nor can one neglect the influence of some of the work of Jespersen, Sommerfelt, and other Scandinavian scholars; the neo-Humboldtian semantic work of Trier, Weisgerber, and others and the German-language tradition of Sprachsoziologie; the "Wörter-und-Sachen" tradition in the study of local communities; the strong traditions of concern with language problems, and literary and standard languages, in the Soviet Union and Japan and work in special fields such as Romance Philology, minor Slavonic languages and cultures, Uralic studies et al. To mention only a few names on the side of social and cultural theory, besides Durkheim, Boas, and Malinowski, Mead, Cassirer, Ogden and Richards, Wittgenstein, Gramsci, Morris, Burke, Merleau-Ponty have influenced general ideas about the social role of language.

Throughout the twentieth century, then, there have been broad conceptions of language and its relevance, and substantive work of value. Nevertheless, the central thread around which understanding of language has advanced in the century has had to do with the analysis of structure internal to language. It is grossly simplified, but not unfair, to see modern structural linguistics as having increasingly defined the methods and results with which any other approach to language must come to terms. The social interests of linguists have not been similarly cumulative, and the linguistic interests of others have been so generalized (with some exceptions in literature and philosophy) as not to articulate with linguistic form as understood by linguists or give guidance to research. The development of linguistics itself, as a selfconscious discipline, has concentrated successively on the conquest of phonology, then morphology and syntax, and now, semantics. Controversies as to units and structures, and as to underlying assumptions, have had successively these foci, although analysis of each "higher" level has had repercussions in levels below.

Three things about this development are especially important here, all of them considerations of function. First, the central development has been a search for structure in relation to but one function of language, that of "reference," "representation," "Darstellung." Other functions, even when admitted, have been treated marginally. Second, there has been a tendency to try to treat a level of structure, once articulated, independently, while neglecting its functional dependence on a "higher" level. Third, the general functioning of language, while of course assumed to be important, indeed vital, to mankind, has been at best postulated, or speculated about, rather than investigated.

In these respects, transformational generative grammar, as formulated by Chomsky, constitutes no departure from structuralist precedent. If anything, it is 
a regression, ruling heterogeneity of speech community, diversity of role among speakers, and stylistic or social meanings, out of court. The introduction of the notions of "competence," "performance," and the "creative aspect of language use" is important but incomplete. "Competence" suggests all the abilities of an actual speaker, but is restricted by Chomsky to just the knowledge of grammar of an ideal speaker; "performance" suggests social action and accomplishment, but is restricted, where positive, to internal psycholinguistic operations, and where social phenomena are concerned, has a negative sense of obscuring grammar; "creativity" does include the construction of appropriate sentences independent of environmental stimuli, but Chomsky analyzes such creativity only as making sentences, not as making sense. The fact that appropriateness is a relation between sentences and contexts, requiring knowledge of both for its explanation, is left out of account.

The integrative approach to sociolinguistic research represents a departure in respect to each of the three points. The issues can be called, respectively, the PLURALITY, the PRIORITY, and the PROBLEMATIC STATUS of the social functions of language. Modern sociolinguistics is not the first to raise these issues, but the first perhaps to pose them as basic to linguistic theory, as the questions which define the foundations of an understanding of language and the practice of linguistics.

As to the plurality of functions, there can be no doubt that the demonstrated possibility of organizing the analysis of language around its referential function shows the fundamental importance of that function to the evolution and use of language. Nevertheless, if we begin, not with formalisms and the autonomy of a discipline as overriding considerations, but with language as it is commonly used, we find the referential function only one among the bases on which discourse is organized and often a minor or peripheral one. We find completeness or explicitness of reference itself a dimension of appropriateness. We find conventional stylistic features and patterns, used for emphasis, clarity, appeal, expression, and the like. And we find referential and stylistic dimensions organized together within conventionally recognized ways of speaking, acts of speech, and speech events. We find, in short, that language is not solely an instrument for naming and describing and conducting rigorous argument. We find it to be an instrument of expression and appeal, of persuasion and command, of deference and insult, of gossip and rebuke; we find it an instrument preferred, eschewed, enjoyed, distrusted, pervasively evaluated, not only in terms of referential adequacy and logical validity, but also in terms of aptness, pleasure, rewards and costs, self-identity and community respect. And we find it to have these roles, not by some wholly external process, some mysterious and magical insertion into social reality, once it has left the grammarian's hand, but in virtue of properties partly specific to it, of features and patterns, as has been said, that serve such meanings, and that have been developed and adapted, often differently and to different degree in different communities, to do so.

As to the functions being problematic, rather than given a priori, the very notions of "language" and "dialect" cannot be relied upon, where it is a matter of their status 
in a community, as current means with current meanings. It is one thing to assign a body of speech, or a linguistic analysis, to some named unit, calling it "English," "Spanish," "Marathi," or the like, because of a stock of resources derived historically from a known source. It is quite another thing to determine what counts as "English," "Spanish," "Marathi" or the like, in a given community, what set of abilities is entailed, in relation to varieties going by the same name elsewhere, and in relation to other varieties in use in the same community. Where convergence has been occurring for some time (as discussed in Gumperz's contribution to this issue), there may be more identity in significant respects between two varieties of different name in the same community, to the point of a single grammar with different lexical representations being possible. A description that does not specify linguistic features in relation to a community of speakers, their repertoires and the uses of these, has hardly validity, relevance, or interest, in such a case. Indeed, from a sociolinguistic standpoint, the same may be said of any description.

Again, as to what counts as "language," what "dialect," as between communities, we find varieties of the same "objective" degree of difference having the status of related dialects in one region, of separate languages in another, according to the political history of each; persons refusing to understand a related dialect, as soon as they recognize it; communities insisting upon translations from a language they readily understand; one language being preferred because of the greeting system it entails; and so on. Everywhere we find "languages" and "dialects" enmeshed in patterns of use and social meanings, partly shaped and defined, as specific varieties of language, by these. We find the same to be true of language itself, as a mode of communication among other modes, here pervading almost every activity, there not; here a community of chatterers, there a community of the taciturn; here language considered indispensable to knowledge or insight, there as mere shell or even barrier; here intertwined with musical expression, there segregated from it; and so on. Thus, the linguistic relativity discussed from W. von Humboldt to Whorf is found to depend upon a more fundamental kind; differences in language can be taken as indications of difference in cognitive orientation only to the extent that the languages in question have each the same role, that of shaping (or expressing) cognitive orientation. Just that equivalence of role is itself problematic. It is relative to the place of a language, or way of speaking, in the history and repertoire of a person or community. Here, as generally, structure depends upon function. The significance of features of language cannot be assessed without knowledge of their social matrix. What features of language are significant, indeed, depends upon the function in question (as Whorf saw, when he spoke of "fashions of speaking," cutting across ordinary linguistic compartments, as what one needs to describe).

For sociolinguistic research, then, what is essential is not only to recognize the plurality and problematic status of functions, but also to take functional questions, questions of social meaning and role, as starting point. Efforts toward a general theory of language as part of social life will remain truncated otherwise, an 
assortment of disjointed parts (or whatever other metaphor of a body and spirit left dismembered and headless one may wish). The case is clear with regard to certain forms of speech that have attracted attention for some time, and speech acts, which have just come into prominence. "Men's and women's speech," "honorific language," "baby language," and the like have been occasionally described, but a review of these studies shows them almost always to involve phenomena that are inescapable in the course of ordinary linguistic work. In the phonology, grammar, or lexicon, one encounters alternates, equivalent in referential meaning, but complementary in terms of social, rather than linguistic, contexts. Social meaning, as embodied in these ways of speaking, in effect is recognized by its intrusion into the organization of a grammar around the function of reference, and its description in effect sets it aside, preserving that organizational base. To go to the trouble of describing the way of speaking of course reflects an interest in it, but if interest depends on intrusion in grammar, then we shall never understand such phenomena, except as occasional curiosities. The implied conclusion would be that in most communities men and women talk entirely alike, that differences in status are never verbally expressed, that nothing verbal could reveal that the addressee of remarks was a baby. Moreover, it would remain impossible to explain the subset of cases in which sex role, status, and generation are marked within the grammar, by alternate forms, in relation to cases in which such differences are marked by selection of forms and by means serving stylistic or social, rather than referential, function (or by combination of all). To explain cases of marking of such meanings in grammars we must be able to compare the full range of cases in which meanings are marked. Given the universal importance of the social meanings in question, their expression in speech probably is universal also; only research taking social meaning as starting point will lead to investigation of that range.

There are many means of speech only occasionally well described, forms of linguistic play and concealment, for example, for which our knowledge is similarly spotty, so that comparison, typology, and explanation are similarly difficult. Of especial importance to linguistic theory now are the characteristics of speech acts. The point to be made here is that speech acts cannot be analyzed or explained within grammar, or indeed within speech, alone. What is linguistically the same utterance, for example, may have the status of a request or of a command, depending not on any feature proper to grammar, but on the social relationship of the parties involved. And rules that govern words as speech acts may be found to govern nonverbal activity as well, as when rules applying to summonses in American society apply to the ringing of a phone or a knock on a door as well. An integrated approach must include the nods, pointings, conventionalized grunts, and the like that enter into commutation with verbal markers of deixis, assent, command, and the like, within paradigmatic sets defined by the function of an act of speech or else betray the accepted criterion of "capturing generalizations." Once embarked upon analysis of speech acts, linguistics must enter into the analysis of communicative acts, or fail. 
The principle applies to the understanding of the social meanings of languages and dialects themselves. On the one hand, a way of speaking may make use of the resources of more than one language or dialect, or in its use of a given language may be inseparable from nonverbal accompaniments, so that the true organization and meaning would be missed if investigation were confined to a linguistically defined language or dialect. On the other hand, the means by which a social meaning, say, intimacy vs. distance, is expressed, may range from choice of pronouns to choice of dialect or language, through choice of voice timbre, of norms as to turn-taking, permissible length of pause, and the like. Again, understanding of individual cases, and a theory, must start from the standpoint of means of speech and the meanings they serve.

This general conclusion can be seen as intrinsic to the development of levels in linguistics. It was the point of Sapir's "Sound patterns in language" (1925) that the same set of sounds might have two different patterns, two different sets the same pattern, when phonological function was taken into account. It has been a point of transformational grammar's critique of a preceding school's conception of "autonomous phonology" that the same phonological elements might have different statuses, and conversely, when grammatical function was taken into account; and that the same overt sentence might have different underlying structures, and conversely, when a deeper level of syntactic function was taken into account. It has been the point of the critique of Chomsky's syntax by generative semantics that different deep structures may have the same status, when semantic function is taken into account; the parallel between this critique of "autonomous syntax" and Chomsky's own critique of "autonomous phonology" has been drawn explicitly. The step to speech acts, and to communicative acts, involves the same logic. Such acts can be conceived as part of a broadly conceived semantics (and Greimas has proposed that sociolinguistics as a whole can be seen as semantic in character); but the possibility of an "autonomous linguistics," where "autonomous" is given the force of isolated and wholly independent, is no longer defensible. If, to be sure, "autonomy" is given the force of "self-governing," master of its own affairs within a larger integrated structure, then there indeed is autonomous linguistics, as there is autonomous syntax and phonology. With regard to his analysis of syntax, Chomsky has convincingly argued that it captures many regularities that are otherwise unexplained; just the same argument justifies a phonology not wholly subordinated to grammar - many regularities are captured that are otherwise hard to explain (e.g. of canonical form). And just the same argument precludes any notion that linguistics will be absorbed and dissolved in the study of sociolinguistics, communication, semiotics, or the like. The regularities it captures, and which are the personal experience of linguists, will continue always to justify a relative autonomy. It is equally clear that thoroughgoing pursuit of generalizations, attention to the functional logic of its own development, must carry linguistics into integration with a broadly conceived study of speech and language as part of social life. This perspective applies to the other end of the connection between sound and 
meaning as well, and shows something of what linguistics has to gain from a more broadly conceived study in territory it unquestionably considers its own. Phonological universals are treated today in terms of referential function alone. Aspiration, for example, is considered only with respect to languages (such as Hindi) in which it serves that function, and not in English. Yet contrasting degree of aspiration of initial stops is a conventional, well understood and widely used, feature of English means of speech. It is a feature defined by stylistic rather than referential function. Possibly aspiration has one or the other conventional significance in every language. The starting point of an inquiry into phonetic and phonological universals, then, must be, what features and relations have conventional significance in all languages? It is a second question to ask, in which languages is that significance referential? in which stylistic? Here again, a true understanding of universals requires starting from a conception of means of speech, not of language as narrowly defined in terms of a single function.

Clearly, from a sociolinguistic standpoint, the meaning of "meaning" must be quite general, along lines sketched more than a generation ago by J. R. Firth (in his paper, "The techniques of semantics" (1935)). There is more to the relation between sound and meaning, which linguistics takes as its concern, than linguistics ordinarily takes into account. Throughout the structures of language, the uses of language, and with regard to languages themselves, two broad types of meaning are interdependent and intertwined. Alongside the "referential" or "representational," there is the "stylistic" or "social." Each has its invariance, complementary to that of the other. Either may be the primary vehicle of a given meaning, as when disgust may be conveyed by choice of words or choice of aspiration. As with men's and women's speech, and the like, so also with dimensions of meaning such as derogation, beseeching, and the like. Sometimes they are found marked in the ordinary grammatical structure of a language (as when derogation is marked by an affix in Chitimacha, or beseeching by an affix in Sierra Zapotec); sometimes such meanings are marked by means, conventional, but not ordinarily incorporated in linguistic description. De Saussure maintained that lexicon and grammar must both be part of linguistic analysis, because a given function was found sometimes expressed in the one, sometimes in the other. The same point applies to meaning generally.

We find on every hand that if the goal of sociolinguistic research is to understand language as part of social life, its approach must be integrative, and indeed, innovative. Its approach cannot be solely additive in the sense of taking results already arrived at, for many of the ways in which language is organized in the service of social life have hardly been identified and analyzed. It cannot be solely correlative of linguistic and social features, as separately identified within the present frames of reference of linguistics and other branches of the human sciences, for the same reason. The greatest challenge for sociolinguistic research is to develop the methods, concepts and findings that will enable one ultimately to approach language, from the linguistic side, not only as grammar, but also 
as language organized in use; from the social side, to approach social structure, cultural pattern, values, and the like, in terms of their realizations in verbal and symbolic action.

The descriptive base for theory and explanation of this sort is almost wholly to be built. The work required will sometimes so involve technical linguistics as to be a direct extension of it. The priority of functional considerations, however, the dependence of recognition of structure upon recognition of function, means that adequate description of a way of speaking must often be from a standpoint heavily dependent on close analysis of social roles, setting, events, and institutions, if the rules of cooccurrence that define its features, and the rules of alternation that govern its use, are to be described. Norms of verbal interaction, including silence; beliefs and attitudes about speech and language, or particular ways of speaking; the emergence, expansion, and decline of standard varieties of languages, and of ways of speaking generally - analysis and causal explanation of many such phenomena must rely primarily upon methods of observation and analysis developed in the social sciences.

In general, relevant research will run a gamut from intimate to minimal involvement with technical linguistics. The development of technical linguistics has been stressed here, because it has been central to advance in understanding of language, and its further development, broadly conceived, is indispensable to specifying what there is to be described and explained. Scholars from different disciplinary backgrounds might well bring out quite different aspects of the lines of work that come together in sociolinguistic research. And this sketch of an integrated approach has quite begged the question of a number of notions that are both essential to it and intrinsically interdisciplinary, notions such as speech community, speech event, domain, genre. Nor has there been space to indicate the implications of an integrated approach for a number of important subjects, such as religion, where a general analysis of ways of speaking and their social functions might shed new light on the domain of religious behavior, even perhaps affecting its delimitation. The sketch does address the fundamental task of sociolinguistic research, I believe, if such research is to be more than a novel name for a hodge-podge of pre-existing activities, pursued helter-skelter. That task is to change the terms of reference for scientific, and informed public discussion, of "language." The task is to put an end to theory and research in terms of "language" and "languages," and to replace it by theory and research in terms of the true forms in which linguistic resources are organized, change and are changed, in human lives. The point of course is not to reject the possibility of generalizations and general theory, but to recognize that the only path to valid generalizations and theory lies THROUGH the sphere of the diverse, socially specific forms of speech that men and women actually have available and use.

The critical analysis outlined here thus implies a definite program of research, and a priority as to what the heart of that research should be, namely, to develop the empirical, methodological, and theoretical means by which to describe and 
explain the concrete organization of speech in society, through efforts to do just that. The initial formulation, MEANS OF SPEECH AND THEIR MEANINGS, is broad enough, I think, to welcome the contributions of any discipline or field of study to the common goal. Still, it must be kept in mind that that goal, though indispensable, is a first step, or first moment, of a fully adequate approach, especially if the general concerns of philosophy and the social sciences are kept in mind. The step is in itself a revolution in the long history of the study of language, a step that first opposes, then transcends, the dominance of "grammar" as the cultural genre in terms of which the place of language in human life is understood. It will be a revolution comparable to that brought about when the possibility of replacing an understanding of men in terms of abstract individuals by an understanding in terms of men in their actual social relations began to be realized in the emergence of social science in the eighteenth and nineteenth centuries. Linguistics in many times and places has continually succeeded in inoculating itself from thoroughgoing social science perspective that would reach to its foundations. The point of the first step, or goal, just stated, the methodological turning point, can in fact be expressed by paraphrase and elaboration of the sixth of the theses of the young Marx on Feuerbach:

Conventional linguistic theory resolves the essence (structure) of speech into a generically human essence. But the essence of man (and, a fortiori, that of speech) is no abstraction inhering in each single individual. In its actuality it entails the ensemble of social relationships.

One who does not go into the critical analysis of this actual essence, is hence compelled:

(1) to abstract from social, historical process and to establish speech as something self-contained, and to presuppose an abstract-isolated-human individual (and correspondingly, an abstract, isolated category of "language" and of "grammar");

(2) to view the essence of man (and speech) merely as "species", as an inner, dumb generality which unites individuals naturally (i.e., spontaneously in ways not requiring analysis, not socially, not through any specific organization of verbal means).

As the paraphrase implies, we must investigate the relationship between the organization of speech in terms of social relationships, and those relationships themselves. What is the reciprocal impact of means of speech, and systems of such, on social life, including therein thought and behavior both, and the impact of social life on such systems? Here one enters into a study of the role of means of speech that has been described earlier in this sketch (the first paragraph of this section (II)), as "part of the maintenance and transformation of socio-cultural order." The initial formulation, means of speech and their meanings, might be taken to encompass only means of speech as verbal objects, or 
to imply a conception of the relation between means of speech and those who use them of stasis or equilibrium. A fully adequate approach must be certain to recognize explicitly the diversity, not only of means of speech, but also of the relationships of means of speech to their social contexts. This diversity of relationships has to do with differential competence, or ABILITIES, on the part of persons in a society, on the one hand, and differential OPPORTUNITIES for access to competence and to use of competence, on the other. The means of speech of a community are a central, significantly autonomous factor, as are the available means for satisfying other essential human needs; but explanation of their function and change lies in the matrix of abilities and opportunities, and the forces at work in determining that matrix. The major role of social science disciplines in this regard is evident.

\section{I I}

How does a field of sociolinguistic research, however conceived or sketched, stand in relation to present patterns of research, among disciplines, and about the world? One thing is clear. Such a field belongs to the science, or study, of man, by man, as a whole, not to any one department of that study, or to any restricted group of participants. The preceding sketch has reflected its author's background in linguistics and anthropology, more precisely, in American linguistics and anthropology. A general field of sociolinguistic research, and the journal, must be as fully interdisciplinary and international as possible.

With regard to disciplines, the field is interdisciplinary, or multidisciplinary, simply because the study of man is parcelled out among disciplines. It may be that now, two centuries after the European Enlightenment, we are witnessing a slow, sometimes tortuous, but inevitable reintegration of the human sciences. As in the late eighteenth century, before the main period of European colonialism, and in the late nineteenth century, during its height, so now, in the late twentieth century, after its collapse, concern for a comprehensive, scientifically informed view of man's origins, nature, and common destiny returns within the sciences of man themselves, with the crucial difference that representatives of all of mankind now participate in forming this view of mankind's history and prospects.

No doubt there will always be centrifugal tendencies in the human sciences, towards boundaries that permit greater rigor of attack on special problems, a more intimate community of colleagues, and that serve, to be sure, less noble motives as well. A centripetal tendency, impelled by recognition of fundamental and urgent problems that escape individual disciplines, now seems to gain ascendance. The disciplinary fragmentation that began to gain dominance a century ago took different forms in different places (evidence itself of the arbitrary component in such divisions), but generally there prevailed claims of the greatest relevance (so that each discipline saw itself to some extent as THE study of man) 
combined with insistence in each on some limited set of subjects and methods as its only proper sphere. It is striking that the dominant impulse in sociolinguistic research has not been toward self-segregation, but toward collaboration and integration. This is in keeping with research at the frontiers of significant knowledge generally today.

The degree of collaboration and integration so far achieved is very uneven, as is its distribution among contributing disciplines. Partly this situation reflects a past unevenness in attention to language and in closeness to linguistics among the human sciences. The term "sociolinguistics" itself reflects this history. It has come to the fore as one in a series of such terms, preceded in prominence by "ethnolinguistics" and "psycholinguistics" particularly. The series reflects the impact of linguistics successively on anthropology (which had partly given it birth), psychology, and then sociology and political science, in the mid-1940s, the 50s, and the 60 s, respectively, leading to efforts to reforge links with the serious study of language, as given new shape by a developing science of linguistic structure. The sequence of impact reflects a decreasing degree of involvement with technical linguistics, from most and longest in anthropology to least and latest in sociology and political science, a difference which remains.

Each term in the series has designated, not a new discipline, but a renewed field of research; the terms have served to mediate the skills and concerns of existing disciplines, with regard to problems that fell between them. Thus semantic description was called "ethnolinguistics," when it fell between ethnography and linguistics, but not now, when it is normal practice in both. (Just so, success for the field of sociolinguistic research may be to make a special name redundant, having made itself an inseparable part of the practice of existing disciplines.) The topics comprised by each term have considerably overlapped, so that linguistic relativity, bilingualism, semantics of kinship, and modes of address, have been discussed under each of the three. The same line of research and work of the same investigator have sometimes been presented, according to context, under the rubric of each of the three.

The latest of the terms, "sociolinguistics," has come to be the most general, since it can suggest a link with not only sociology, but the social sciences as a whole. In various quarters, to be sure, "sociolinguistics" has taken on different primary meanings, such as study of urban dialects, or fine-grained study of social inter-action, or survey and analysis of multilingual situations. Here the term is taken with the general scope that has been indicated, comprising all aspects of language as part of social life.

The series of terms does betray a certain bias. In form, each term implies that the social science component modifies linguistics, which has the central role. There is an irony here, in that the terms and the research they designate have involved social scientists perhaps more than linguists. There is a certain tension too. Some scholars would prefer to designate their work as "sociology of language," or some other term, in order to make clear that their concern is with social science, not linguistics. 
There may be a feeling that technical linguistics is not really necessary, or at best quite subordinate, to the study of major social problems, such as those of language policy, the role of standard languages, and the like. There may be a reciprocal feeling on the part of others who cannot conceive of any worthwhile study of language that is not informed by present-day linguistics. This situation poses a problem for the journal, as to terminology and as to policy, and it is proposed to resolve it in the following way.

As to title, "sociolinguistic" appears an indispensable adjective for the field of research with which the journal is concerned. The noun, "sociolinguistics," is useful and likely to be frequently used, but use of either term does not imply any concern to establish a novel discipline, a novel set of academic departments, or the like, but simply a common field of concern. In the editor's view the fragmentation of the human sciences has already gone much too far, and reintegration is desperately needed. "An international journal of sociolinguistic research," then, does accurately describe the journal's scope and purpose, and serves as an appropriate subtitle. At the same time, "Language in Society" has been chosen as principal title. In the initial stage of planning of the journal, opinion was found to favor such a title, over a title such as "Sociolinguistic Research," by about two to one. Reasons, positive and negative, on both sides varied, but the principal considerations are that "Language in Society" is clearly a general and enduring name. It has the advantages of not making acceptance of the journal dependent on acceptability of a term which does not yet have generally agreed upon scope and meaning, and of not suggesting that the journal is confined to any one connotation that "sociolinguistic" might currently have. Two things about the title of the journal must be emphasized. The linking term is "in," not the "and" that a casual reader or hearer might substitute. And the journal's title is meant to indicate that the journal is concerned with all the human sciences, since in their studies of language all must be concerned with its social matrix.

As to policy, there is no requirement that contributions to the journal be conceived of or labeled as "sociolinguistic." It suffices if they are significant contributions within its scope. Individual contributions will range from predominantly linguistic to predominantly social in character, but it is hoped that there will be something of each in all. The journal must necessarily reflect the main lines of research as they are. By its existence, and contiguity within its pages, it can hope (in the words of the late A. L. Kroeber) "to advance the day of further larger reconstitution."

With regard to geography, the degree of international collaboration and integration so far achieved is exceedingly uneven. The languages of publication must of necessity be English and French; despite the wide international use of these two languages, the restriction is regretted. The editorial board is international but there is concentration of scholars from North America, and to a lesser extent, Europe. This concentration reflects the disproportionately greater level of sociolinguistic activity in these regions; it is an aim of the journal to encourage a better 
balanced development of sociolinguistic research throughout the world. In aid of that aim, a number of issues will feature a set of articles on sociolinguistic research in a country or region, by scholars resident there and also scholars elsewhere. It is hoped that such a set of articles may bring out problems of major concern and the general significance of sociolinguistic research in the area. 